\title{
LA INVIOLABILIDAD DEL DOMICILIO EN LA CONSTITUCIÓN DE 1869
}

SILVIA PASCUAL LÓPEZ

$$
\text { Doctora en Derecho }
$$




\title{
LA INVIOLABILIDAD DEL DOMICILIO EN LA CONSTITUCIÓN DE 1869
}

\author{
P०ᄋ \\ -SILVIA PASCUAL LÓPEZ \\ Doctora en Derecho
}

En la Constitución de 1869 se aborda, con verdadera intención codificadora, la problemática de los derechos de la persona, con el afán de recuperar el discurso liberal revolucionario, varias veces proclamado y ninguna asumido ${ }^{1}$.

Viene a plantearse, de este modo, la pugna entre quienes conciben los derechos fundamentales como esencialidad ilegislable ${ }^{2}$ y quienes conciben su naturaleza contingente ${ }^{3}$.

1 Maestro Buelga, Gonzalo, "Derechos ilegislables y Derechos contingentes en la Constitución de 1869», Historia Contemporánea, 12 (1995), págs. 280-305.

2 Es el caso por influencia norteamericana.

Vid. OltRA, Joaquín, La Influencia Norteamericana en la Constitución Española de 1869, Instituto de Estudios Administrativos, Madrid, 1972, págs. 111-116.

3 Tendencia que ya proclama Alcalá Galiano: "Al hablar de ciertos derechos abstractos, considerados por algunos como naturales e imprescriptibles en los hombres, declaré muchos de ellos falsos a mi entender, impugné otros como mal explicados y peligrosos, insinué que no hay otros derechos políticos que los nacidos de la misma sociedad, ya formada, y de las leyes, y condené todas las máximas abstractas y vagas como pésima base para sentar en ella la fábrica de las constituciones [...]" (AlCALA Galiano, Antonio, Lecciones de Derecho Político, Centro de Estudios Constitucionales, Madrid, 1984, pág. 279). 
El referente constitucional de las Cortes Constituyentes de 1869 es la Constitución federal de los Estados Unidos, no por federal, sino por iusnaturalista a ultranza. Tal concepción incorpora una nueva fundamentación del poder político como salvaguarda de la libertad, afirmada en el reconocimiento de unos derechos inherentes al ser humano y por lo mismo, anteriores a cualquier regulación positiva y al propio Estado.

En el texto que elaboran los constituyentes de 1869 subyace la tensión ideológica entre la tradición americana que invoca el Derecho Natural, no sólo para legitimar los derechos individuales, sino también la sociedad política, y la influencia francesa que contempla la cuestión desde la óptica de una institucionalización del poder político derivada de la necesidad de expresar su ruptura con el absolutismo ${ }^{4}$.

La valoración ilegislable de los derechos es compartida, en diversos grados, por la minoría republicana, por una mayoría instalada en la Comisión Constitucional y, finalmente, por posiciones doctrinarias, de menor presencia en el debate parlamentario.

El primer grupo tomará como referencia la primera enmienda de la Constitución norteamericana, tanto en su alusión directa a la no regulación por ley de los derechos en ella contenidos, como a la exigua configuración de los mismos.

Así se manifiestan Estanislao Figueras ${ }^{5}$ y Emilio Castelar6.

Entre los integrantes de la Comisión, Segismundo Moret, muestra reparos:

"[...] À vuelta de lo que los señores de la minoría republicana llaman ilegislabilidad de los derechos, [...], hay una cosa que es legislable, que es el ejercicio de esos derechos individuales [...]. Por una razón sencillísima: porque si no se legislan no habrá tales derechos individuales. Por ejemplo, la seguridad individual es un derecho completamente ilegislable, convenido; pero es necesario saber cómo va á ser efectivo ese derecho; es preciso decir en la ley cómo se ha de

4 Todo ello derivado de la fórmula de 1789, 1793 y 1798.

5 Estos derechos son la base y límite de toda ley. Estanislao FIGUERAs, Diario de Sesiones de las Cortes Constitucionales (DSCC), 6 de abril de 1869.

6 Los derechos individuales [...] son [...] completamente ilegislables [...] las generaciones venideras no podrán creer nunca, absolutamente nunca, no ya que los derechos individuales se hayan negado, pero ni siquiera que [...] se hayan escrito [...] (Emilio CASTELAR, DSCC, 7 de abril de 1869). 
ejercer, y tenemos que fijar en la Constitución las garantías que han de asegurarle $[\ldots]$ )?

En la misma línea, Manuel Becerra:

"[...] Hay aqui una confusión de palabras; se dice si son ó no legislables: no lo son en cuanto á que no es la ley la que los da, sino que parten de la misma naturaleza; pero sí lo son desde el momento en que la ley tiene que determinar el uso, la forma, el temperamento, para el caso en que los derechos de un individuo se ponen en contacto con los derechos de los demás [...]"8.

Las tesis doctrinarias expresan la continuidad del moderantismo que rompió con el espíritu de la Constitución de Cádiz.

Su portavoz, a quien veremos protagonizar el proceso de la Restauración, es Antonio Cánovas del Castillo:

"[...] Es el establecimiento de los derechos individuales, inseparable de la manera en que se organice y constituya el Estado, porque éste ha de representar precisamente el derecho absoluto de cada uno delante del derecho absoluto de cada otro [...]"9.

Con independencia de tensiones dialécticas, va a quedar en el ambiente constituyente una manera mimética de concebir los derechos fundamentales al amparo de una ilegislabilidad para la que se quería, incluso, una declaración constitucional de fundamentación iusnaturalista.

Los derechos no debian ser legislados ni por la misma Constitución, a la que también le estará vetado el desarrollo de los mismos.

Son derechos naturales, ilimitados y sólo los problemas derivados de su colisión con otros derechos individuales, se remitiría a la solución judicial10.

7 Segismundo Moret, DSCC, 16 de abril de 1869.

8 Manuel BeCERRA, DSCC, 13 de abril de 1869.

9 Frente a las posiciones iusnaturalistas, Cánovas subraya la confrontación de los derechos del Estado que se sobreponen, incluso, a los derechos individuales.

Antonio Cánovas del CAstillo, DSCC, 8 de abril de 1869.

10 Emilio CASTELAR, DSCC, 7 de abril de 1869. (La manifestación más evidente de esta posición afectó al debate de los artículos 5,17 y 18). 
Al final... el texto constitucional no asumirá la ilegislabilidad de los derechos. Todo se redujo a un mero debate ideológico.

Implícitamente quedó consagrada la fórmula de los derechos contingentes (remisión legal de los derechos).

La atención prestada a los derechos individuales es, sin duda, la nota más característica de la Norma fundamental que va a elaborar$\mathrm{se}^{11}$. El Dictamen de la Comisión redactora así lo manifiesta:

"Ya no se trata hoy de los derechos políticos que directamente influyen en la vida pública y que se resumian generalmente en la libertad de imprenta más o menos garantizada, y en el derecho electoral peor ó mejor amparado. Semejante base de legislación, que con la garantía de la seguridad personal y de la propiedad formaba el ideal de las opiniones políticas de otros tiempos y fue el objeto de las anteriores Constituciones, es hoy insuficiente y estrecha para contener el poderoso movimiento, la rica vida que de todas partes se desborda y que ha dado á la "revolución" de Setiembre, á diferencia de todas las anteriores, un carácter social, aún no bien definido, pero decisivo ya para la Constitución que de ella ha de nacer. Por eso, por primera vez en España, el proyecto de Constitución desarrolla en vasta y acabada serie de derechos individuales, condiciones indeclinables que forman el carácter del ciudadanon ${ }^{12}$.

Resultado de la gran preocupación e intensa discusión que dichos derechos provocan entre los constituyentes, es el Título I ( $D e$ los españoles y sus derechos), que acoge treinta y un artículos dedicados a su exhaustivo y explicito reconocimiento. Asistimos, por primera vez en nuestra historia constitucional, bajo un epígrafe que incluye la palabra derechos, a un amplio elenco de derechos fundamentales informadores de la parte dogmática ${ }^{13}$.

11 Astarloa Villena, Francisco, "Los derechos y libertades en las Constituciones históricas españolas", Revista de Estudios Políticos, 92 (1996), pág. 231.

Carro Martínez, Antonio, La Constitución Española de 1869, Ediciones Cultura Hispánica, Madrid, 1952, pág. 131.

12 En DSCC, 30 de marzo de 1869.

13 Los derechos y libertades contemplados por el texto constitucional de 1869 se pueden agrupar de la siguiente forma con estas denominaciones:

- Derechos civiles:

- Principio de seguridad personal (art, 2).

- Garantía judicial de la libertad (art. 4).

- Garantía del habeus corpus (arts. 3 y 12).

- Garantía procesal y penal (art. 11). 
Hay quien estima que esta forma de proceder parece más propia de una ley orgánica que de un texto constitucional14. Prueba de ello, es que parte de su regulación acabará nutriendo la Ley de Enjuiciamiento Criminal de $1882^{15}$.

Con todo, va a ser la Constitución de 1869 la que acuñe la inviolabilidad del domicilio con verdadero sentido de naturaleza y significación, muy por encima, por ejemplo, de lo que podía postular la Constitución gaditana de 1812 . 5, dispone:

La primera redacción de uno de los artículos más debatidos, el

«Nadie podrá entrar en la casa de un español ó extranjero residente en España sin su consentimiento, excepto en los casos urgentes de incendio, inundación ú otro peligro análogo, ó de agresión ilegítima procedente de adentro, ó para ayudar á persona que desde allí pida socorro.

Sólo el juez competente podrá decretar y llevar á efecto de día, pero nunca de noche, la entrada en la casa de un español ó extranjero residente en España y el registro de sus papeles ú otros efectos» ${ }^{16}$.

- Libertad de residencia y domicilio (art. 6).

- Inviolabilidad del domicilio (art. 5).

- Inviolabilidad de la correspondencia (art. 7).

- Derecho de propiedad (art. 13).

- Libertad de movimiento (art. 26).

- Libertad de establecimiento en territorio español y de ejercicio en él de industria por parte de los extranjeros (art. 25).

- Libertad de enseñanza (art. 24).

- Derechos públicos:

- Derecho de libertad de expresión (art. 17.2).

- Derecho de reunión pacífica (arts. 17.3 y 18).

- Derecho de asociación (arts. 17.4 y 19).

- Derechos políticos:

- Derecho de sufragio (art. 16).

- Derecho de petición (art. 17.5).

- Derecho a ejercer empleos o cargos públicos (art. 27).

Vid. Cavero latalllade, Íñigo, y Zamora Rodriguez, Tomás, Constitucionalismo Histórico de España, Editorial Universitas, Madrid, 1995, págs. 176-181.

14 BECKER, Jerónimo, La Reforma Constitucional en España. Estudio histórico-crítico acerca del origen y vicisitudes de las Constituciones españolas, Imprenta de Jaime Ratés Martín, Madrid, 1923, pág. 205.

15 EsPin TEMPLADO, Eduardo, "Fundamento y alcance del derecho fundamental a la inviolabilidad del domicilion, Centro de Estudios Constitucionales, 8 (1991), pág. 42.

16 En DSCC, 30 de marzo de 1869. 
De inmediato van a producirse discrepancias sobre el carácter y contenido de este precepto. Así, mientras para Figueras la inviolabilidad del domicilio no está garantizada en este artículo porque en él se admiten multitud de interpretaciones - ¿Por qué no habéis de poner aqui taxativamente los casos en que se podrá entrar en el domicilio ajeno sin consentimiento del dueño? ${ }^{17}$-, Cánovas propone que con la redacción casuística de los supuestos exceptuados de la regla general de este derecho es necesaria la restricción del mismo por la administración de justicia, debido a la inexistencia de la fórmula, recogida en anteriores constituciones, de remitir a leyes posteriores el establecimiento de las limitaciones de esta garantía ${ }^{18}$.

El fundamento $y$ alcance de este precepto es objeto de varias enmiendas:

- Francisco Javier Moya (progresista) presenta la primera de ellas al párrafo segundo del artículo del proyecto, finalmente aprobada.

"Fuera de estos casos", sólo el juez competente podrá decretar y llevar á efecto de día, pero nunca de noche, la entrada en la casa de un español ó extranjero residente en España [...]»19.

Estamos ante una simple corrección de estilo para acentuar que los casos no contemplados en el primer párrafo no precisan permiso de autoridad alguna, mientras que todos los demás supuestos, no

17 DSCC, 6 de abril de 1869.

18 Antonio CÁNOVAS DEL CASTILlo: «[...] ¿Podrá, sin embargo, cumplirse la justicia humana desde el momento en que casos concretos de violación indispensable, instantánea, de domicilio, casos definibles, precisos, en que la autoridad debe penetrar en domicilio ageno, no estén expresamente comprendidos en la Constitución? (DSCC, 8 de abril de 1869).

19 Sin embargo, Antonio de los Ríos y Rosas confía en que así como uen Inglaterra, donde la inviolabilidad del domicilio tiene una gran inflexibilidad, la magistratura ha sabido, sin violar la ley, sin aplacarla de una manera farisáica, ha sabido combinar la persecución de los crímenes con la inviolabilidad del hogar doméstico. Lo que sucede en Inglaterra sucede en los Estados Unidos, y eso podrá suceder y sucederá en España cuando esté arreglada la organización del poder judicial [...]" (DSCC, 9 de abril de 1869).

Esta enmienda es firmada por los progresistas Francisco Javier Moya, Jacinto Ballesteros, Tomás Rodríguez Pinilla, Leandro Rubio, Manuel de Sandoval, Vicente Morales Díaz y Joaquín Bañón (DSCC, 15 de abril de 1869). 
recogidos en el mismo, necesitan de dicha autorización únicamente concedida por los jueces ${ }^{20}$.

- Gonzalo Serraclara (republicano) defiende el carácter inatacable a la garantía de la protección domiciliaria con esta segunda enmienda:

"Nadie podrá entrar en la casa de un español ó extranjero residente en España, sin su consentimiento "21.

Su justificación está centrada en que no se puede admitir absolutamente que nadie se entrometa en su casa, casa de un ciudadano libre, de la que es dueño, rey y absoluta majestad. El interés de Serraclara por determinar un carácter inatacable a la salvaguarda de la inviolabilidad domiciliaria, responde a sus anhelos por prevenir antiguas arbitrariedades sufridas por motivos políticos ${ }^{22}$, que no quedan eliminadas por el simple hecho de que la capacidad de decisión para decretar y llevar a cabo la entrada en morada ajena se traslade de la autoridad administrativa a la judicial. Hay que realizar, en su opinión, todo lo necesario para que mañana no puedan echarnos en cara imprevisiones en este punto tan importante como es el domicilio. En este sentido, declara que existe un profundo respeto hacia el domicilio en muchas naciones de Europa como, por ejemplo, Inglaterra - My home is my castle ${ }^{23}$ - donde hace muchos años a la autoridad no se le permitió penetrar en la morada de una mujer, nueva Juana la Loca, para dar sepultura al cadáver de su marido, que conservaba en su casa muerto, porque la viuda se opuso a ello 24 .

Estas ideas calificadas de exageradamente individualistas por el demócrata Vicente Romero Girón, secretario de la Comisión, no pros-

20 En DSCC, 16 de abril de 1869.

21 La segunda enmienda es presentada y firmada por los republicanos: Gonzalo Serraclara, Pablo Alsina, José Antonio Guerrero, Luis Blanc, Santiago Soler y Plá, Francisco Suñer y Capdevila y Francisco de Paula del Castillo (DSCC, ibidem).

22 Vid. DSCC, 19 de abril de 1869.

23 La morada, considerada una fortaleza donde el inglés es el rey, se encuentra rodeada de una serie de derechos y soberanía que impiden su impune violación. RUIz del CASTILlo y CatALÁn de Ocón, Carlos, Manual de Derecho Político, Reus, Madrid, 1939, pág. 377. pág. 617.

Pérez Serrano, Nicolás, Tratado de Derecho Político, Civitas, Madrid, 1976,

24 Cfr. DSCC, 16 de abril de 1869. 
perarán al argumentarse que no hay derecho individual que a la vez no sea un derecho social. Todos los derechos tienen el carácter de relación y, por ello, no hay derecho que en sí mismo sea absoluto aunque sí lo sea su fundamento. Por tanto, no se puede preservar un principio antisocial solamente imaginable en el Robinson solitario de la isla ${ }^{25}$.

- Mayor complicación ofrece la enmienda presentada por el progresista Sabino Herrero, apoyada por su correligionario Adriano Curiel y Castro.

"Que en el párrafo primero, á las palabras "agresión ilegítima", se añada "de fuerza material"; que á la conclusión del mismo párrafo se adicione: "ó para capturar á un delincuente que visto ó cogido in fraganti huye y se refugia en casa propia ó agena, ó al que yendo preso se fugase, ó al que tenga contra sí mandamiento de prisión". Y por último, que en el segundo párrafo se supriman las palabras "de dia, pero nunca de noche" ${ }^{26}$.

Curiel y Castro declara que agresión ilegítima puede ser una palabra ofensiva o acción insignificante que dirija un individuo que esté dentro de la casa a otro que se encuentre fuera de la misma. Cualquiera de estas agresiones, que no por ser pequeñas dejan de ser ilegítimas, pueden servir de pretexto para entrar en el domicilio de un ciudadano, dejando este derecho completamente en el aire. No obstante, esta vaguedad desaparece añadiendo después de agresión ilegitima los términos de fuerza material porque, de esta manera, ya no cabe interpretación alguna y no se puede tomar como excusa una simple palabra ofensiva o insulto para allanar la morada ${ }^{27}$.

El liberal Moret, en nombre de la Comisión, no considera necesario aclarar el contenido de agresión ilegítima por estimar que está perfectamente definida en derecho: la agresión ilegítima supone siempre la violación del derecho de otro, y que se ha cometido siempre con la circunstancia de ser contraria á la ley. Por supuesto existen casos dudosos, pero para ellos están la jurisprudencia de los tribunales, las

25 DSCC, ibidem.

26 Dicha enmienda también es firmada por: Juan Paradela (demócrata), Valentín Vázquez Curiel (Unión Liberal), Manuel Jontoya (progresista), Julián Martínez y Ricart (progresista) y Manuel Sandoval (progresista) (DSCC, 19 de abril de 1869).

27 DSCC, ibidem. 
costumbres del foro y las costumbres generales del país. Las palabras fuerza material no son bastante claras, no están bien definidas, ni responden al sistema general establecido por la Comisión. Si se añadiesen dichos términos podría darse el caso de que agresiones ilegítimas en el domicilio, por no estar perfectamente claras o dentro del derecho, quedaran impunes. Estamos hablando, v.gr., de arrojar ácido sulfúrico desde un balcón. En este supuesto no hay fuerza material y sin embargo, hay una completa violación del derecho en el sentido de que no sólo puede quedar desfigurado el rostro sino que, incluso, puede ocasionar la muerte28.

El segundo punto de esta enmienda corre mejor suerte, siendo aprobado por la Comisión. Con ello se quiere decir que la segunda redacción del artículo 5 recoge lo relativo a delito in fraganti:

"[...] Sin embargo, cuando la autoridad ó sus agentes persigan á un delincuente hallado in fraganti, y éste se refugiare en su domicilio, podrán aquellos penetrar en él sólo para el acto de la aprehensión. Si se refugiare en domicilio ajeno, procederá el requerimiento del dueñon 29 .

No obstante, los otros supuestos - el que yendo preso se fugare, y el que tuviera contra sí mandamiento de prisión- no alcanzan la misma fortuna. En opinión de los redactores del proyecto, la idea genérica de delito in fraganti comprende el supuesto de huida, mientras que el auto de prisión se encuentra consignado en el procedimiento general para entrar en el domicilio ${ }^{30}$.

La última sugerencia de esta enmienda relativa a la supresión de las palabras de día pero nunca de noche, tampoco es admitida por entenderse que no puede sustraerse la inviolabilidad domiciliaria a la noche ${ }^{31}$. (En la mente de muchos parlamentarios aún están recientes los sobresaltos y atropellos motivados por frecuentes visitas nocturnas, protagonizadas por agentes de la autoridad del régimen absoluto) 32 .

28 DSCC, ibid.

29 En DSCC, 21 de abril de 1869.

30 DSCC, 22 de abril de 1869.

31 DSCC, 19 de abril de 1869.

32 En esta misma línea, y ante la práctica habitual de desalojar conventos en algunos momentos de la Revolución del 68 , Vicente Manterola solicita la inclu- 
- Una nueva enmienda encabezada por el demócrata José Jimeno Agius y aprobada íntegramente por la Comisión, es la base definitiva del párrafo segundo:

"Fuera de estos casos, la entrada en la casa de un español ó extranjero residente en España, lo mismo que el registro de sus papeles ú otros efectos, sólo podrán decretarse por juez competente y llevarse á cabo durante las horas del dia» ${ }^{33}$.

- La nueva redacción del artículo 5 se complementa con la propuesta del republicano Pedro Moreno que relaciona dicho artículo con el 7, sobre protección de correspondencia, indicando que el registro de papeles debe llevarse siempre a cabo en presencia del reo 0 , en su defecto, de la persona más interesada que esté a su favor, v.gr. familia o dos vecinos ${ }^{34}$.

El texto finalmente aprobado queda así:

«Nadie podrá entrar en el domicilio de un español ó extranjero residente en España sin su consentimiento, excepto en los casos urgentes de incendio, inundación ú otro peligro análogo, ó de agresión ilegítima procedente de adentro, ó para auxiliar á persona que desde allí pida socorro.

Fuera de estos casos, la entrada en el domicilio de un español ó extranjero residente en España, y el registro de sus papeles ó efectos, sólo podrán decretarse por Juez competente y ejecutarse de día.

El registro de estos papeles y efectos tendrá siempre lugar á presencia del interesado ó de un individuo de su familia; y en su defecto de dos testigos vecinos del mismo pueblo.

Sin embargo, cuando un delincuente hallado in fraganti, y perseguido por la Autoridad o suś agentes se refugiare en su domicilio, podrán éstos penetrar en él sólo para el acto de la aprehensión. Si se refugiare en domicilio ajeno, procederá requerimiento al dueño de éste".

sión expresa en el artículo que de la inviolabilidad de domicilio no pueden ser exceptuadas las comunidades religiosas. Esta propuesta no se aceptó.

En LorCa Siero, Antonio, Las Cortes Constituyentes de 1869-1871. Las Cortes y la Constitución de 1869, Editorial MAN, León, 1995, vol. I, pág. 278.

33 La suscriben: José Jimeno Agius (demócrata), Rafael Prieto (progresista), Nicolás Soto (progresista), Francisco Javier Moya (progresista), Julián Pellón y Rodriguez (Unión Liberal), Luis de Molini (demócrata) y Pedro Pastor y Huerta (demócrata) (DSCC, 19 de abril de 1869).

34 DSCC, 22 de abril de 1869. 
El debate constituyente de este extenso y minucioso artículo presenta otro aspecto de interés, como es el relacionado con el bien jurídico protegido.

Cobran sentido las palabras de Figueras: Vosotros decís que habéis venido á consagrar la inviolabilidad del domicilio. Al reconocer el derecho de la familia era consecuencia indispensable que reconocierais la inviolabilidad del domicilio ${ }^{35}$, compartidas por Romero Girón que considera al domicilio como la manifestación de un derecho en sus más altas relaciones, en las relaciones de la familia ${ }^{36}$. Por su parte, Moret entiende que el domicilio, las cuatro paredes de nuestra casa, encierra lo que hay entre nosotros de legítimo y de sagrado, el amor, el cariño, la propiedad, los recuerdos [...], cuanto en la constitución de nuestra vida y de nuestro afecto está guardado ${ }^{37}$.

La redacción definitiva del artículo 5 presenta unos caracteres que lo singularizan respecto de cualquier texto anterior.

Por de pronto, el domicilio o la casa deja de verse sólo como la fortaleza inatacable de posibles detenciones arbitrarias de la autoridad, y comienza a entenderse como el ámbito de desarrollo de la vida íntima personal y familiar.

Llama la atención, a parte de su extensión, la utilización del término domicilio como objeto de protección jurídica, arrinconando la denominación habitual de casa, más ambigua y propia del medievo. Además, la garantia se hace extensiva de forma explícita a españoles y extranjeros residentes en España. Por residente se entiende encontrarse en España, no de paso y sí, con intención de continuidad.

Las circunstancias que autorizan la entrada legítima en domicilio ajeno se encuentran perfectamente detalladas: consentimiento del titular, estado de necesidad, flagrante delito y autorización judicial. Se concilia así el carácter cuasi sagrado de la inviolabilidad domiciliaria como derecho natural, individual, con la necesidad social de garantizar una convivencia pacífica.

El fundamento de este precepto, además de garantizar la propiedad - domicilio - y la libertad y seguridad individuales - libertad personal del morador-, comienza a relacionarse con la moderna consideración de este derecho como protección de la vida privada de las

35 DSCC, 6 de abril de 1869.

36 DSCC, 16 de abril de 1869.

37 DSCC, 8 de abril de 1869. 
personas. De ahí que el registro de papeles y efectos se rodee de las mismas garantías que la propia violación de la morada, entendiéndose que la inviolabilidad del domicilio no sólo incluye la violación del mismo, sino también otras acciones igualmente reprochables como el registro.

Por eso, el registro domiciliario -en presencia del interesado, familiares, o en su defecto dos vecinos del mismo pueblo- exige, al igual que la entrada, que se efectúe de día, nunca de noche, por entender que esta última puede amparar abusos más difíciles de darse en diurnidad.

En conexión con el artículo 5, el 8 exige motivación en el auto que autorice el registro, incluyendo, en su párrafo segundo, las consecuencias de su incumplimiento: cuando el autor carezca de este requisito, o cuando los motivos en que se haya fundado se declaren en juicio ilegítimos o notoriamente insuficientes, la persona [...] cuyo domicilio hubiere sido allanado, [...] tendrá derecho a reclamar del Juez que haya dictado el auto una indemnización proporcional al daño causado, pero nunca inferior a 500 pesetas.

Por su parte, el artículo 9 establece que la Autoridad gubernativa que infrinja lo presente en el artículo 5 , incurrirá en delito de allanamiento de morada, quedando además sujeta a la indemnización prescrita en el párrafo $2{ }^{\circ}$ del artículo anterior.

Desde el punto de vista penal, la inviolabilidad domiciliaria encuentra regulación y protección en los artículos 215, 216 y 217 del Código Penal de 18 de junio de $1870^{38}$, restringiéndose por vez primera los sujetos activos del delito a los funcionarios que no fueran autoridad judicial, aunque los jueces podían ser responsables de la violación nocturna del domicilio 39 .

38 Francisco Silvela lo denominó Código de verano de 1870 porque las Cortes aprobaron el proyecto, tras un brevísimo debate de dos sesiones (15 y 17 de junio de 1870) en que se examinan los temas políticos de la reforma, aplazando su discusión definitiva hasta la reanudación de las sesiones, pasado el verano. En ÓNECA, José Antón, Derecho Penal, Akal, 2." ed., Madrid, 1986, pág. 77.

39 Artículo 215: Incurrirán en las penas de suspensión en sus grados mínimo y medio y multa de 125 á 1.250 pesetas:

1. ${ }^{\circ}$ El funcionario público que no siendo Autoridad judicial, y no estando en suspenso las garantías constitucionales, entrare en el domicilio de un español ó extranjero sin su consentimiento, á no ser en los casos y con los requisitos previstos en los párrafos primero y tercero del art. $5 .^{\circ}$ de la Constitución. 
El allanamiento perpetrado por particulares contra la voluntad del morador, y efectuado con violencia o intimidación se tipifica en los artículos 504, 505 y 506, los cuales no suponen novedad respecto de los Códigos Penales de 1848 y 1850.

Por último, la Ley de Orden Público de 23 de abril de 1870, en su artículo 10, establece los procedimientos a seguir para poder entrar en el domicilio de cualquier español o extranjero residente en España, sin su consentimiento, y para examinar sus papeles y efectos. La entrada y registro en el domicilio no puede hacerse sino por la propia autoridad o por un delegado suyo, provisto de orden formal y escrita, y a presencia del dueño o encargado de la casa, o de uno o más individuos de su familia, de dos vecinos de la propia casa o de las inmediatas, 0 de dos cualesquiera del mismo pueblo ${ }^{40}$.

$402 .^{\circ}$ El funcionario público que no siendo Autoridad judicial y no estando tampoco en suspenso las garantías constitucionales, registrare los papeles de un ciudadano ó extranjero y efectos que se hallaren en su domicilio, á no ser que el dueño hubiere prestado su consentimiento.

Si no devolviere al dueño inmediatamente después del registro los papeles $y$ efectos registrados, la pena será la inmediatamente superior en grado.

Si los sustrajere y se los apropiare, será castigado como reo de delito de robo con violencia en las personas [...].

Artículo 216: La Autoridad judicial que fuera de los casos previstos en los párrafos primero y tercero del art. $5 .^{\circ}$ de la Constitución, y no estando en suspenso las garantías constitucionales, entrare de noche en el domicilio de un español ó extranjero sin su consentimiento, incurrirá en la pena de suspensión en sus grados mínimo y medio, y multa de 125 á 1.250 pesetas.

Artículo 217: En la misma pena incurrirá la Autoridad judicial que registrare de noche en el domicilio de un español ó extranjero sus papeles y efectos, á no ser con su consentimiento.

Artículo 10: La Autoridad civil podrá también entrar en el domicilio de cualquier español o extranjero residente en España, sin su consentimiento y examinar sus papeles y efectos. Pero nada de esto podrá verificarse sino por la misma autoridad o por un delegado suyo, provisto de orden formal y escrita. En uno $y$ otro caso, el reconocimiento de la casa, papeles y efectos tendrá lugar siempre que sea presenciado por el dueño o encargado de la misma, o uno o más individuos de su familia, y por dos vecinos de la propia casa o de las inmediatas, si se hallasen en ellas, $y$ en su defecto por dos vecinos del mismo pueblo.

No hallando en ella al dueño o encargado de la casa ni a ningún individuo de la familia, se hará el reconocimiento a la presencia únicamente de los dos vecinos indicados, levantándose acta del reconocimiento, que firmará con ellos la Autoridad o su delegado.

Cuando un delincuente contra el orden público fuere sorprendido in fraganti, $y$, perseguido por la Autoridad civil o sus subordinados o dependientes, se refugiase en su propio domicilio o en el ajeno, podrán éstos penetrar en él, pero sólo para el efecto de la aprehensión. 
De este precepto es reseñable la referencia a la autoridad civil, en sustitución de autoridad judicial, entendida como la autoridad gubernativa a la que se hace alusión en posteriores artículos cuando se diferencia autoridad civil, judicial y militar, o cuando señala que en los supuestos de rebelión y sedición en capital de provincia, la autoridad civil es el gobernador civil de la provincia.

Con todo ello, este texto constitucional, en relación a la protección del domicilio, presenta una minuciosidad, alcance y fundamento hasta ahora desconocidos, con unos criterios que impiden al máximo el abuso de poder. Su consideración permite afirmar que estamos ante una de las Constituciones más avanzadas y garantistas de todo el Derecho Constitucional español.

\section{BIBLIOGRAFÍA}

Alcalá Galiano, Antonio, Lecciones de Derecho Político, Centro de Estudios Constitucionales, Madrid, 1984.

Astarloa Villena, Francisco, "Los derechos y libertades en las Constituciones históricas españolas", Revista de Estudios Políticos, 92 (1996), págs. 207-250.

BECKER, Jerónimo, La Reforma Constitucional en España. Estudio histórico-crítico acerca del origen y vicisitudes de las Constituciones españolas, Imprenta de Jaime Ratés Martín, Madrid, 1923.

Carro Martínez, Antonio, La Constitución Española de 1869, Ediciones Cultura Hispánica, Madrid, 1952.

Cavero Latalllade, Íñigo, y Zamora Rodríguez, Tomás, Constitucionalismo Histórico de España, Editorial Universitas, Madrid, 1995.

EsPín TEMPLADO, Eduardo, "Fundamento y alcance del derecho fundamental a la inviolabilidad del domicilion, Centro de Estudios Constitucionales, 8 (1991), págs. 39-53.

LorCa Siero, Antonio, Las Cortes Constituyentes de 1869-1871. Las Cortes y la Constitución de 1869, Editorial MAN, León, 1995, vol. I.

Maestro Buelga, Gonzalo, "Derechos ilegislables y Derechos contingentes en la Constitución de 1869", Historia Contemporánea, 12 (1995), págs. 280-305. 
OLTRA, Joaquín, La Influencia Norteamericana en la Constitución Española de 1869, Instituto de Estudios Administrativos, Madrid, 1972.

ÓNECA, José Antón, Derecho Penal, Akal, 2. ${ }^{a}$ ed., Madrid, 1986.

Pérez Serrano, Nicolás, Tratado de Derecho Político, Civitas, Madrid, 1976.

Ruiz del Castillo y Catalan de Ocón, Carlos, Manuial de Derecho Político, Reus, Madrid, 1939. 